\title{
MODEL FOR DETERMINING FLOW DIAMETER AND ECONOMIC VELOCITY IN WATER ELEVATING SYSTEMS
}

\author{
JOÃO L. ZOCOLER, FRANCISCO C. BAGGIO FILHO, LUÍS A. F. OLIVEIRA, \\ AND FERNANDO B. T. HERNANDEZ
}

Received 28 September 2004; Revised 13 April 2006; Accepted 18 April 2006

The purpose of this paper was to develop a model for calculating the economical flow diameter and velocity, by obtaining the economical diameter, using Swamee's friction factor equation, by minimizing the total annual cost. The application of the model to a regular supply condition showed that the diameter of the actual condition, $250 \mathrm{~mm}$, compared with the diameter calculated by the mode, at the same tariff as that applied to the property (ground), $284.1 \mathrm{~mm}$, involved the necessity to generate, transmit, and distribute extra electrical energy, due to the higher load loss caused by the original diameter, approximately $30800 \mathrm{kWh} /$ year. This means that in one year, the consumer would spend $\mathrm{R} \$ 2,804.00$ more on pumping cost alone.

Copyright (c) 2006 João L. Zocoler et al. This is an open access article distributed under the Creative Commons Attribution License, which permits unrestricted use, distribution, and reproduction in any medium, provided the original work is properly cited.

\section{Introduction}

Water elevating systems have been used since ancient times for many human activities, such as to provide drinking water for humans and animals, to produce food, and for industrial production. The economical analysis of such systems is very important, since the capital invested in them is often high, and their cost can make the activities that use them either feasible or not.

The costs of a water elevating system are influenced by many variables; however, most of them are related to the physical features of the place, which make them constant when talking about a particular case. The main variables are piping length and type of material, topographic levelness, flow requirements, pressure at the end of the piping, and length of the high voltage electrical line if the pumping is done by electrical motors. The diameter of the discharge piping is a variable that causes intense variation in the cost of the system and is, theoretically, not affected by the physical features of the place [8].

Doing the pumping at low flow speed results in a relatively big diameter, involving higher piping costs and lower costs of pumps, engines, and drive power, due to the lower

Hindawi Publishing Corporation

Mathematical Problems in Engineering

Volume 2006, Article ID 17263, Pages 1-17

DOI 10.1155/MPE/2006/17263 
manometric heights. On the other hand, if pumping is done at a high speed, the diameter will be relatively smaller; raising the manometric height and consequently, costs of pumps, engines, and power will be higher. Hence, the choice of a suitable diameter should be done after economical assessment [3], seeking the minimum total annual cost, in terms of present value, considering the fixed annual cost resulting from the initial investment, and the variable annual cost resulting mainly from the pumping and maintenance [9].

Some formulas have been developed, based on the criterion of minimum total cost, and Bresses's is probably the most widely used formula applied to continuous operation:

$$
\phi=K Q^{0.5} \quad(\text { Bresse })
$$

where

$(\phi)$ discharging piping diameter $(\mathrm{m})$;

$(Q)$ outflow $\left(\mathrm{m}^{3} \mathrm{~s}^{-1}\right)$;

$(K)$ constant that basically depends on the relation between the unit power cost for the elevating station (including spare parts, conservation, and disbursement), and the laid piping unit of length. This usually costs between $R \$ 0.7$ and 1.3.

Note. Jacques Antoine Charles BRESSE (1822-1883) was a French applied mathematician, born in Vienne, Isère. He was Professor at the Ecole Nationale Supérieure des Ponts et Chaussées, Paris.

When the discharging installation is not continuous, the economical diameter can be calculated by the Forchheimer formula or by the Brazilian Association of Technical Norms formula, (Associação Brasileira de Normas Técnicas_ABNT) mentioned by [7]:

$$
\begin{gathered}
\phi=1.46 X^{0.25} \sqrt{Q} \quad(\text { Forchheimer }) \\
\phi=1.3 T^{0.25} \sqrt{Q} \quad(\mathrm{ABNT})
\end{gathered}
$$

where

$(\phi)$ piping diameter $(\mathrm{m})$;

(Q) outflow of the system $\left(\mathrm{m}^{3} \mathrm{~s}^{-1}\right)$;

$(X)$ number of working hours for the installation per year divided by 8760 ;

(T) number of working hours for the installation per day divided by 24.

Note. Philipp Forchheimer (1852-1933), was an Austrian hydraulician from Vienne, teaching Hydraulics in Aachen and Graz.

In addition to this, other researchers have developed formulas or models for calculating the economical diameter, the following being quoted: Camp [2], Cuomo and Villela [4], Babbitt [1], Deb [5], Lencastre [6], Coiado and Rivelli [3], and Zocoler [8].

The Zocoler model [8] enables the total annual cost of a water elevating system driven by internal combustion engines or by electric motors to be estimated and minimized. In the case of electric motors, the electrical power tariffs and special discounts given to rural consumers are also considered. Application of the model to an irrigation water elevating system that demanded an outflow of $245.19 \mathrm{~m}^{3} \mathrm{~h}^{-1}$ and whose original zinc 
João L. Zocoler et al. 3

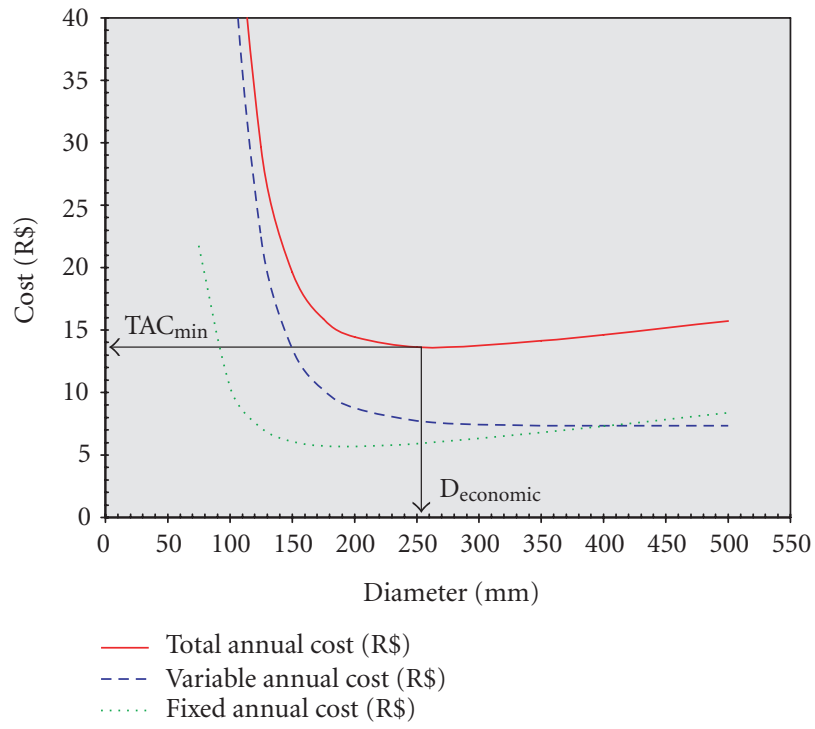

Figure 1.1. Annual cost of the water elevating system related to the piping diameter.

steel discharge piping had a diameter $216.4 \mathrm{~mm}$ (equivalent diameter) showed that the most economic theatrical diameter would be $265.5 \mathrm{~mm}$ (Figure 1.1), when the drives were powered by electricity according to the green tariff rates and with a special discount for irrigation at night, a condition considered to be more advantageous to the consumer.

In the same study, it was also found that the costs of the system operated by diesel engines were higher than those for electric motors at all the electrical power tariff rates. When the model sensitivity was analyzed, the author found that the total annual cost of the system by electricity would only be higher, in comparison with the diesel system, if the high-tension line was longer than $14186 \mathrm{~m}$.

The purpose of this work was to develop a model for calculating the economical discharge velocity by obtaining the economical diameter through the use of the Swamee equation for the friction factor, to minimize the total annual cost. The economic flow velocity can be used as a reference for calculating irrigation systems and/or broadly, for water supply. It was also proposed to apply the model to a regular supply condition in order to make a comparison between the existing diameter and the diameters calculated by the model.

\section{Methodology}

The economic discharge velocity is obtained by calculating the discharge piping diameter that will give the lowest total annual cost (TAC) of the system; that is to say, the diameter when $d \mathrm{TAC} / d \phi=0$. The TAC is a result of the sum of the fixed annual cost (FAC) and the variable annual cost (VAC).

In the fixed annual cost (FAC), the annual amortization (AAM) and the annual remuneration (ARE) of the capital invested in the system components are considered, that 
is to say, pipes, pumps, accessories in general, engines/motors (combustion or electric), starters, transformers, pump house, and infrastructure in general.

Basically, the VAC takes into account the pumping annual cost (PAC) and the maintenance and repair annual costs (MRAC).

In order to obtain the economic diameter, the model was developed in two phases, named first and second approach.

2.1. First approach. In the first approach, the fixed annual cost (FAC) was defined only taking into account the discharge piping diameter, which directly affects the manometric height of the system and consequently, the pump power, engine, and other necessary components to drive it (active components), and evidently also affects power, maintenance, and repair costs, that is to say, the annual variable cost. However, the investment in the pump, engine, and other active components was not considered in the fixed annual cost (in the first approach), because the functional relation between the price and the pump power is not precise, when the model or commercial series of homologous pumps used in the system is not defined, due to the broad variation of the possible manometric height in the first approach. Example: the multicellullar pump model price is considerably higher than that of the standard unicellular model, even though the two absorb a similar amount of power.

However, with the first approach to the economical diameter, the manometric high would have a smaller amplitude variation in the second approach, which enables the pump series (or model) to be used in the system to be defined and consequently, the use of a more precise functional relation for estimating the fixed annual cost.

Thus, the fixed annual cost (FAC, in \$-currency units) in the first approach was calculated by the following equation:

$$
\mathrm{FAC}=\frac{\operatorname{La}^{b}(1-R) r}{(1+r)^{\mathrm{AP}}-1}+\frac{\operatorname{La} \phi^{b}(1+r)^{\mathrm{AP}}-1}{\left[\sum_{n=1}^{\mathrm{AP}}(1+r)^{n}\right]+1}
$$

where

(L) length of the discharging piping $(\mathrm{m})$;

$(\phi)$ discharge piping diameter $(\mathrm{m})$;

(a) and $(b)$ coefficients of multiplicative regression adjustment between the discharge piping diameter and its cost (Zocoler, 1994);

$(R)$ residual value of system;

$(r)$ annual interest rate;

(n) polynomial exponent (natural number);

(AP) amortization period or useful life of the piping (years).

The first term of (2.1) corresponds to the unitary annual amortization of system, and the second to the unitary annual remuneration of the capital. With the objective of facilitating the derivation of the function, the pumping annual cost (PAC, in \$) was defined only in relation to the load loss, since the geometric height of the water elevation $\left(h_{g}\right)$ and the necessary piezometric load at the end of the discharge piping $\left(h_{p}\right)$ are 
constant values in the function and, being added to the load loss $\left(h_{f}\right)$, result in the total manometric height $(\mathrm{H})$.

Thus, $o$ pumping annual cost of the system load loss when combustion engines drive the pumps was calculated by the following equation:

$$
\mathrm{PAC}=\frac{Q \gamma c_{o} c_{u} t_{a}}{735 \eta_{b(1)}} h_{f}
$$

where

(Q) system outflow $\left(\mathrm{m}^{3} \mathrm{~s}^{-1}\right)$;

$(\gamma)$ specific weight of the water $\left(\mathrm{Nm}^{-3}\right)$;

$\left(\eta_{b(1)}\right)$ hydraulic pump efficiency (1st approach);

$\left(c_{o}\right)$ unit consumption of the combustion enginewhich in general is $0.000225 \mathrm{~m}^{3}$ $\mathrm{hp}^{-1} \mathrm{~h}^{-1}$

$\left(c_{u}\right)$ unit fuel cost $\left(\$ \mathrm{~m}^{-3}\right)$;

$\left(t_{a}\right)$ annual system-operating $(\mathrm{h})$;

$\left(h_{f}\right)$ load loss occurring in the discharge piping $(\mathrm{m})$, which can be calculated by the following equation:

$$
h_{f}=\frac{16 Q^{2} L}{\pi^{2} 2 g} \frac{f}{\phi^{5}}
$$

where

$(g)$ gravity acceleration, considered to be $9.80 \mathrm{~m} \mathrm{~s}^{-2}$;

( $f$ ) friction factor, obtained by the Swamee formula (1993), enables " $f$ " to be calculated either for the laminar flow or also for the turbulent flow. It can be obtained by

$$
f=\left\{\left(\frac{64 \pi \phi v}{4 Q}\right)^{8}+9.5\left[\operatorname{In}\left(\frac{e}{3.7 \phi}+\frac{5.74}{(4 Q / \pi \phi \nu)^{0.9}}\right)-\left(\frac{2500 \pi \phi \nu}{4 Q}\right)^{6}\right]^{-16}\right\}^{0.125},
$$

where

(v) kinematical viscosity $\left(\mathrm{m}^{2} \mathrm{~s}^{-1}\right)$;

(e) internal absolute piping roughness $(\mathrm{m})$.

The annual system pumping cost, when electric motors drive the pumps was calculated by the equation

$$
\mathrm{PAC}=\mathrm{ADI}+\mathrm{ACI}+\mathrm{AAD}
$$

where

(ADI) annual demand invoicing (\$);

(ACI) annual consumption invoicing $(\$)$;

(AAD) annual adjustment referring to the power factor $(\$)$, considered null when the installation has capacitor bank to increase the factor to the minimal level required by the concessionaire company for exemption by it. 
The first two terms of (2.5) are calculated in conformity with the electric power billing system, that is, it is conventional or hour-seasonal, in addition to whether or not special discount is granted on the consumption tariff for the subgroup A4-rural irrigation consumers with exclusive irrigation meters, according to the DNAEE Directive no. 105 from April 3rd, 1992.

Thus, in accordance with the scope of the work, equations were defined for calculating $\mathrm{ADI}$ and ACI for the billing systems: conventional with and without the special discount for irrigation, and green hourly-seasonal with and without special discount for irrigation.

(i) Conventional billing without discount:

$$
\mathrm{ADI}=\operatorname{MDDT}_{c}(12-d)+0.10 d \operatorname{MDDT}_{c},
$$

where

$\left(\mathrm{DT}_{c}\right)$ conventional demand tariff $\left(\$ \mathrm{~kW}^{-1}\right)$;

(d) number of months completed per year when the elevating system remains off and thus, invoicing of demand occurs, corresponding to $10 \%$ of the highest demand measured in the last 11 months, that is, the $M D_{\max }(O B S: 0 \leq d \leq 11$ always);

(MD) measured power demand (kW), obtained by the equation

$$
\mathrm{MD}=\frac{Q \gamma}{1000 \eta_{\mathrm{mb}(1)}} h_{f}
$$

where

$\left(\eta_{\mathrm{mb}(1)}\right)$ expected effectiveness of electrical motor and hydraulic pump together (1st approach)

$$
\mathrm{FAC}=\mathrm{MC}_{y} \mathrm{CT}_{y}
$$

with

$\left(\mathrm{CT}_{c}\right)$ conventional consumption tariff $\left(\$ \mathrm{kWh}^{-1}\right)$;

$\left(\mathrm{MC}_{y}\right)$ measured consumption of electrical power in the year $(\mathrm{kWh})$, obtained by

$$
\mathrm{MC}_{y}=\frac{Q \gamma t_{y}}{1000 \eta_{\mathrm{mb}(1)}} h_{f}
$$

where

$\left(t_{y}\right)$ elevating system-operating time in the year $(\mathrm{h})$.

(ii) Conventional billing with discount:

(ADI) the same as in (2.6)

$$
\mathrm{ACI}=\mathrm{CT}_{c}\left[\mathrm{MC}_{\mathrm{st}}(1-\mathrm{fdct})+\mathrm{MC}_{c}\right]
$$


where

(fdct) fraction of discount on the consumption tariff $(0.70,0.80$ or 0.90 , depending on the region of the country);

$\left(\mathrm{MC}_{\mathrm{st}}\right)$ measured consumption of electrical power at the special time for irrigation (from $11 \mathrm{pm}$ to $5 \mathrm{am})$ in the year ( $\mathrm{kWh})$;

$\left(\mathrm{MC}_{c}\right)$ measured consumption of electrical power at the complementary time to the special time for irrigation in the year (kWh).

The measured consumption of electrical power at the special time for irrigation in the year is obtained by the equation

$$
\mathrm{MC}_{\mathrm{st}}=\frac{Q \gamma t_{\mathrm{st}}}{1000 \eta_{\mathrm{mb}(1)}} h_{f}
$$

where

$\left(t_{\mathrm{st}}\right)$ system-operating time at special time for irrigation in the year $(\mathrm{h})$.

The measured consumption of electrical power at the complementary time for irrigation in the year is obtained by the equation

$$
\mathrm{MC}_{c}=\frac{Q \gamma t_{c}}{1000 \eta_{\mathrm{mb}(1)}} h_{f},
$$

where

$\left(t_{c}\right)$ system-operating time complementary to the special for irrigation in the year $(\mathrm{h})$. (iii) Hourly-seasonal green billing without discount:

$$
\mathrm{ADI}=\left\lfloor\mathrm{MDDT}_{g}+(\mathrm{MD}-\mathrm{DA}) \mathrm{ED}_{g}\right\rfloor(12-d)+0.10 d \mathrm{MDDT}_{g},
$$

with

(DA) demand agreed with the concessionary electric energy company (kW);

$\left(\mathrm{DT}_{g}\right)$ green demand billing $\left(\$ \mathrm{~kW}^{-1}\right)$;

$\left(\mathrm{ED}_{g}\right)$ exceeding green demand tariff $\left(\$ \mathrm{~kW}^{-1}\right)$, which is only applied if (i) the measured demand is higher than $10 \%$ of the agreed demand, when the agreed demand exceeds $100 \mathrm{~kW}$, (ii) the measured demand exceeds $20 \%$ of the agreed demand, when the agreed demand is from $50 \mathrm{~kW}$ to $100 \mathrm{~kW}$. Therefore, the term (MD-DA)ED $g$ of (2.13) is not applied if the contract is adequate, fact considered in the development of the model:

$$
\mathrm{ACI}=\mathrm{MC}_{\mathrm{pw}} \mathrm{CT}_{g \mathrm{pw}}+\mathrm{MC}_{\text {off pw }} \mathrm{CT}_{g \text { off pw }}+\mathrm{MC}_{\mathrm{pd}} \mathrm{TC}_{g \mathrm{pd}}+\mathrm{CM}_{\text {off pd }} \mathrm{TC}_{g \text { off pd }},
$$

where

$\left(\mathrm{MC}_{\mathrm{pw}}\right)$ measured consumption $(\mathrm{kWh})$ in peak time (from $5 \mathrm{pm}$ to $9 \mathrm{pm}$ or defined by the company) in wet period;

$\left(\mathrm{MC}_{\mathrm{off} p w}\right)$ measured consumption $(\mathrm{kWh})$ in off-peak time (complementary hours to the peak time) in wet period;

$\left(\mathrm{MC}_{\mathrm{pd}}\right)$ measured consumption $(\mathrm{kWh})$ in peak time in dry period;

$\left(\mathrm{CM}_{\text {off pd }}\right)$ measured consumption (kWh) in off-peak time in dry period; 
$\left(\mathrm{CT}_{g \mathrm{pw}}\right)$ green consumption tariff in peak time in wet period $\left(\$ \mathrm{kWh}^{-1}\right)$;

$\left(\mathrm{CT}_{g \text { off pw }}\right)$ green consumption tariff in off-peak time in wet period $\left(\$ \mathrm{kWh}^{-1}\right)$;

$\left(\mathrm{CT}_{g \mathrm{pd}}\right)$ green consumption tariff in peak time in dry period $\left(\$ \mathrm{kWh}^{-1}\right)$;

$\left(\mathrm{CT}_{g \text { off pd }}\right)$ green consumption tariff in off-peak time in dry period $\left(\$ \mathrm{kWh}^{-1}\right)$.

The measured consumption in peak time in wet period is obtained by the equation

$$
\mathrm{MC}_{\mathrm{pw}}=\frac{Q \gamma t_{\mathrm{pw}}}{1000 \eta_{\mathrm{mb}(1)}} h_{f},
$$

where

$\left(t_{\mathrm{pw}}\right)$ system-operating time in peak time in wet period $(\mathrm{h})$.

The measured consumption in off-peak time in wet period is obtained by the equation

$$
\mathrm{CM}_{\mathrm{off} \mathrm{pw}}=\frac{Q \gamma t_{\mathrm{off} \mathrm{pw}}}{1000 \eta_{\mathrm{mb}(1)}} h_{f},
$$

where

$\left(t_{\text {off pw }}\right)$ system-operating time in off-peak time in wet period $(\mathrm{h})$.

The measured consumption in peak time in dry period is obtained by

$$
\mathrm{MC}_{\mathrm{pd}}=\frac{Q \gamma t_{\mathrm{pd}}}{1000 \eta_{\mathrm{mb}(1)}} h_{f},
$$

where

$\left(t_{\mathrm{pd}}\right)$ system-operating time in peak time in dry period $(\mathrm{h})$.

The measured consumption in off-peak time in dry period is obtained by the equation

$$
\mathrm{MC}_{\text {off pd }}=\frac{Q \gamma t_{\mathrm{off} p d}}{1000 \eta_{\mathrm{mb}(1)}} h_{f},
$$

where

$\left(t_{\text {off pd }}\right)$ system-operating time in off-peak time in dry period $(\mathrm{h})$;

(iv) Hourly-seasonal green billing with discount.

(ADI) idem to (2.13):

$$
\begin{aligned}
\mathrm{ACI}= & \mathrm{MC}_{\mathrm{pw}} \mathrm{CT}_{g \mathrm{pw}}+\left[\mathrm{MC}_{\text {off pcw }}+\mathrm{MC}_{\text {stw }}(1-\mathrm{fdct})\right] \mathrm{CT}_{g \text { off pw }} \\
& +\mathrm{MC}_{\mathrm{pd}} \mathrm{CT}_{g \mathrm{pd}}+\left[\mathrm{MC}_{\text {off pcd }}+\mathrm{MC}_{\text {std }}(1-\mathrm{fdct})\right] \mathrm{CT}_{g \text { off pd }},
\end{aligned}
$$

where

$\left(\mathrm{MC}_{\mathrm{stw}}\right)$ measured consumption $(\mathrm{kWh})$ in special time for irrigation in wet period;

$\left(\mathrm{MC}_{\mathrm{off} \mathrm{pw}}\right)$ measured consumption $(\mathrm{kWh})$ in the off-peak time, complementary to the special time for irrigation, in wet period;

$\left(\mathrm{MC}_{\text {std }}\right)$ measured consumption $(\mathrm{kWh})$ in special time for irrigation in dry period;

$\left(\mathrm{MC}_{\text {off pcd }}\right)$ measured consumption $(\mathrm{kWh})$ in the off-peak time, complementary to the special time for irrigation, in dry period. 
The measured consumption in special time for irrigation in wet period is obtained by the equation

$$
\mathrm{MC}_{\mathrm{stw}}=\frac{Q \gamma t_{\mathrm{stw}}}{1000 \eta_{\mathrm{mb}(1)}} h_{f}
$$

where

$\left(t_{\mathrm{stw}}\right)$ system-operating time in special time for irrigation in wet period $(\mathrm{h})$.

The measured consumption in the off-peak time, complementary to the special time for irrigation, in wet period is obtained by the equation

$$
\mathrm{MC}_{\mathrm{off} \mathrm{pcw}}=\frac{Q \gamma t_{\mathrm{off} \mathrm{pcw}}}{1000 \eta_{\mathrm{mb}(1)}} h_{f},
$$

where

$\left(t_{\text {off pcw }}\right)$ system-operating time in the off-peak time, complementary to the special time for irrigation, in wet period $(\mathrm{h})$.

The measured consumption in special time for irrigation in dry period is obtained by the equation

$$
\mathrm{MC}_{\mathrm{std}}=\frac{Q \gamma t_{\mathrm{std}}}{1000 \eta_{\mathrm{mb}(1)}} h_{f}
$$

where

$\left(t_{\text {std }}\right)$ system-operating time in the special time for irrigation in dry period $(\mathrm{h})$.

The measured consumption in the off-peak time, complementary to the special time for irrigation, in dry period is obtained by the equation

$$
\mathrm{MC}_{\mathrm{off} p \mathrm{pd}}=\frac{Q \gamma t_{\mathrm{off} p \mathrm{pd}}}{1000 \eta_{\mathrm{mb}(1)}} h_{f}
$$

where

$\left(t_{\text {off pcd }}\right)$ system-operating time in the off-peak time, complementary to the special time for irrigation, in dry period $(\mathrm{h})$.

In the model, only the losses in the discharge piping were considered. However, in case the losses of localized loads and sucking piping (which in most of the cases are small enough to be disregarded in comparison with discharge piping) have to be disregarded, the part equivalent to them should just be added to the length of the discharge piping $(L)$ (the virtual lengths method).

In the first approach the annual maintenance and repair cost, which is calculated considering it as a fraction $(\mathrm{m})$ of the seed money for the system, was not considered, because the indicial investment considered only the discharge piping.

Since the economic discharge velocity comes from the discharge piping diameter, with $d \mathrm{CAT} / d \phi=0$, and because of the large number of equations and elements present in 
them, the elements that were considered constant were isolated, in order to facilitate their derivation, and define those operating with the variable $\phi$ :

$$
\begin{aligned}
& K_{1}=\frac{(1-R) \cdot r}{(1+r)^{\mathrm{AP}}-1}, \\
& K_{2}=\frac{(1+r)^{\mathrm{AP}}-1}{\left[\sum_{n=1}^{\mathrm{AP}}(1+r)^{n}\right]+1}, \\
& K_{3}=\frac{Q \gamma c_{o} c_{u} t_{a}}{735 \eta_{b(1)}} \\
& K_{4}=\frac{16 Q^{2} L}{\pi^{2} 2 g}, \\
& K_{5}=\frac{Q \gamma}{1000 \eta_{\mathrm{mb}(1)}}(12-d)+0.1 d \frac{Q \gamma}{1000 \eta_{\mathrm{mb}(1)}}, \\
& K_{6}=\frac{Q \gamma}{1000 \eta_{\mathrm{mb}(1)}} .
\end{aligned}
$$

As the friction factor " $f$ " from the load loss formula (2.3) is also a function of the diameter, the following elements, which were considered constant, were isolated, in order to facilitate its derivation:

$$
\begin{aligned}
& K_{7}=\left(\frac{64 \pi \nu}{4 Q}\right)^{8}, \\
& K_{8}=\frac{e}{3.7}, \\
& K_{9}=\frac{5.74}{(4 Q / \pi \nu)^{0.9}}, \\
& K_{10}=\frac{2500 \pi \nu}{4 Q} .
\end{aligned}
$$

Substituting the constants $K_{7}, K_{8}, K_{9}$, and $K_{10}$ in (2.4), one gets

$$
f=\left\{K_{7} \phi^{8}+9.5\left[\ln \left(\frac{K_{8}}{\phi}+K_{9} \phi^{0.9}\right)-K_{10} \phi^{6}\right]^{-16}\right\}^{0.125} .
$$

Finally, doing the substitutions, the general equation of the total annual cost (TAC) and its derivate in relation to the discharge piping diameter $(d \mathrm{TAC} / d \phi)$ to minimize the total annual cost of the systems by combustion and by electricity in both billing 
João L. Zocoler et al. 11

modalities and in both types of application (with discount and without discount for irrigation) are obtained by the following equations.

(i) Combustion system:

$$
\begin{gathered}
\mathrm{TAC}=\left(K_{1}+K_{2}\right) \operatorname{La} \phi^{b}+K_{3} K_{4} \frac{f}{\phi^{5}}, \\
\frac{d \mathrm{TAC}}{d \phi}=\left(K_{1}+K_{2}\right) \operatorname{Lab} \phi^{b-1}-5 f \phi^{-6}\left(K_{3} K_{4}\right)+\frac{d f}{d \phi} \phi^{-5}\left(K_{3} K_{4}\right) .
\end{gathered}
$$

(ii) Electricity system in conventional billing without discount:

$$
\begin{aligned}
\mathrm{TAC}= & \left(K_{1}+K_{2}\right) \mathrm{La} \phi^{b}+\left(K_{4} K_{5} T D_{c}+K_{4} K_{6} t_{y} C T_{c}\right) \frac{f}{\phi^{5}}, \\
\frac{d \mathrm{TAC}}{d \phi}= & \left(K_{1}+K_{2}\right) \mathrm{Lab} \phi^{b-1}-5 f \phi^{-6}\left(K_{4} K_{5} D T_{c}+K_{4} K_{6} t_{y} C T_{c}\right) \\
& +\frac{d f}{d \phi} \phi^{-5}\left(K_{4} K_{5} D T_{c}+K_{4} K_{6} t_{y} C T_{c}\right) .
\end{aligned}
$$

(iii) Electricity system in conventional billing with discount:

$$
\begin{aligned}
\mathrm{TAC}= & \left(K_{1}+K_{2}\right) \mathrm{La} \phi^{b}+\left(K_{4} K_{5} D T_{c}+K_{4} K_{6} t_{c} C T_{c}+K_{4} K_{6} t_{\mathrm{st}}(1-\mathrm{fdct}) C T_{c}\right) \frac{f}{\phi^{5}}, \\
\frac{d \mathrm{TAC}}{d \phi}= & \left(K_{1}+K_{2}\right) \mathrm{Lab} \phi^{b-1}-5 f \phi^{-6}\left(K_{4} K_{5} D T_{c}+K_{4} K_{6} t_{c} C T_{c}+K_{4} K_{6} t_{\mathrm{st}}(1-\mathrm{fdct}) C T_{c}\right) \\
& +\frac{d f}{d \phi} \phi^{-5}\left(K_{4} K_{5} D T_{c}+K_{4} K_{6} t_{c} C T_{c}+K_{4} K_{6} t_{\mathrm{st}}(1-\mathrm{fdct}) C T_{c}\right) .
\end{aligned}
$$

(iv) Electricity system in hourly-seasonal green billing without discount:

$$
\begin{gathered}
\mathrm{TAC}=\left(K_{1}+K_{2}\right) \mathrm{La} \phi^{b}+\left(K_{4} K_{5} D T_{g}+K_{4} K_{6} t_{\mathrm{pw}} C T_{g \mathrm{pw}}+K_{4} K_{6} t_{\mathrm{off} \mathrm{pw}} C T_{g \text { off pw }}\right. \\
\left.+K_{4} K_{6} t_{\mathrm{pd}} T C_{g \mathrm{pd}}+K_{4} K_{6} t_{\text {off pd }} T C_{g \text { off pd }}\right) \frac{f}{\phi^{5}} \\
\frac{d \mathrm{TAC}}{d \phi}=\left(K_{1}+K_{2}\right) \mathrm{Lab} \phi^{b-1}-5 f \phi^{-6}\left(K_{4} K_{5} D T_{g}+K_{4} K_{6} t_{\mathrm{pw}} C T_{g \mathrm{pw}}+K_{4} K_{6} t_{\text {off pw }} C T_{g \text { off pw }}\right. \\
\left.+K_{4} K_{6} t_{\mathrm{pd}} C T_{g \mathrm{pd}}+K_{4} K_{6} t_{\text {off pd }} C T_{g \text { off pd }}\right) \\
+\frac{d f}{d \phi} \phi^{-5}\left(K_{4} K_{5} D T_{g}+K_{4} K_{6} t_{\mathrm{pw}} C T_{g \mathrm{pw}}+K_{4} K_{6} t_{\text {off pw }} C T_{g \text { off pw }}\right. \\
\left.+K_{4} K_{6} t_{\mathrm{pd}} C T_{g \mathrm{pd}}+K_{4} K_{6} t_{\text {off pd }} C T_{g \text { off pd }}\right) .
\end{gathered}
$$


12 Economic velocity in pumping

(v) Electricity system in hourly-seasonal green billing with discount:

$$
\begin{aligned}
\mathrm{TAC}=\left(K_{1}+K_{2}\right) \mathrm{La} \phi^{b}+ & \left(K_{4} K_{5} D T_{g}+K_{4} K_{6} t_{\mathrm{pw}} C_{g \mathrm{pw}}+K_{4} K_{6} t_{\mathrm{off} \mathrm{pcw}} C T_{g \text { off pw }}\right. \\
& +K_{4} K_{6} t_{\mathrm{stw}}(1-\mathrm{fdct}) C T_{g \text { off pw }}+K_{4} K_{6} t_{\mathrm{pd}} C T_{g \mathrm{pd}} \\
& \left.+K_{4} K_{6} t_{\text {off pcd }} C T_{g \text { off pd }}+K_{4} K_{6} t_{\mathrm{std}}(1-\mathrm{fdct}) C T_{g \text { off pd }}\right) \frac{f}{\phi^{5}}
\end{aligned}
$$

$$
\begin{aligned}
& \frac{d \mathrm{CAT}}{d \phi}=\left(K_{1}+K_{2}\right) \mathrm{Lab} \phi^{b-1}-5 f \phi^{-6}\left(K_{4} K_{5} D T_{g}+K_{4} K_{6} t_{\mathrm{pw}} C_{g \mathrm{pw}}+K_{4} K_{6} t_{\mathrm{off} p \mathrm{pw}} C T_{g \text { off pw }}\right. \\
& +K_{4} K_{6} t_{\mathrm{stw}}(1-\mathrm{fdct}) C T_{g \text { off pw }}+K_{4} K_{6} t_{\mathrm{pd}} C T_{g \mathrm{pd}} \\
& \left.+K_{4} K_{6} t_{\text {off pcd }} C T_{g \text { off pd }}+K_{4} K_{6} t_{\text {std }}(1-\mathrm{fdct}) C T_{g \text { off pd }}\right) \\
& +\frac{d f}{d \phi} \phi^{-5}\left(K_{4} K_{5} D T_{g}+K_{4} K_{6} t_{\mathrm{pw}} C_{g \mathrm{pw}}+K_{4} K_{6} t_{\mathrm{off} \mathrm{pcw}} C T_{g \text { off pw }}\right. \\
& +K_{4} K_{6} t_{\mathrm{stw}}(1-\mathrm{fdct}) C T_{g \text { off pw }}+K_{4} K_{6} t_{\mathrm{pd}} C T_{g \mathrm{pd}} \\
& \left.+K_{4} K_{6} t_{\text {off pcd }} C T_{g \text { off pd }}+K_{4} K_{6} t_{\text {std }}(1-\text { fdct }) C T_{g \text { off pd }}\right) \text {. }
\end{aligned}
$$

The equations of " $f$ " and " $d f / d \phi$ " were not explained in (2.28), (2.30), (2.32), (2.34), (2.36) and taking (2.26), its derivative in relation to the discharge piping diameter $(d f / d \phi)$ is obtained by

$$
\begin{aligned}
\frac{d f}{d \phi}=0.125 & \times \frac{\left.8 K_{7} \phi^{7}-152\left(\left(-K_{8} / \phi^{2}+0.9\left(K_{9} / \phi^{0.1}\right)\right) /\left(K_{8} / \phi+E \phi^{0.9}\right)-6 K_{10} \phi^{5}\right)\right)}{\left\{\ln \left(K_{8} / \phi+K_{9} \phi^{0.9}\right)-K_{10} \phi^{6}\right\}^{17}} \\
& \times \frac{1}{\left\{K_{7} \phi^{8}+9.5 /\left[\ln \left(K_{8} / \phi+K_{9} \phi^{0.9}\right)-K_{10} \phi^{6}\right]^{16}\right\}^{0.875}} .
\end{aligned}
$$

Hence, equaling (2.28), (2.30), (2.32), (2.34), and (2.36) to zero, the economical discharge piping diameter is obtained, in the first approach.

2.2. Second approach. In the second approach, the "active" system components which represent a significant part of the initial investment are included, such as, the pump and the engine/motor (combustion and electricity) together with the accessories to drive them, which directly affect the optimization of the system. These components change the fixed annual cost of the system and because, together with the discharge piping, they are the most significant part of the initial investment, they enable the maintenance and repair annual cost to be included more accurately.

Another aspect to be considered is that because the series (or model) of pump to be used was defined, the effectiveness of the motor pump unit (or pump only for combustion system) presents a more precise value in comparison with the one used in the first approach, in which there would be an expected, but uncertain value. At this rate, in all 
terms of TAC in which the constants $K_{5}$ and $K_{6}$ are present, the values of the effectiveness expected in the less precise first approach $\left(\eta_{\mathrm{mb}(1)}\right)$ should be substituted by the expected effectiveness in the more precise second approach $\left(\eta_{\mathrm{mb}(2)}\right)$.

Considering the above, as regards (2.27), (2.29), (2.31), (2.33), and (2.35), the following terms are also added:

$$
\left(K_{1}+K_{2}\right) K_{6} K_{4} \frac{f}{\phi^{5}} C_{\text {ua }}+\left(K_{6} K_{4} \frac{f}{\phi^{5}} C_{\text {ua }}+\mathrm{La} \phi^{b}\right) \mathrm{m},
$$

where

$\left(C_{\mathrm{ua}}\right)$ unitary cost of the active system components $\left(\$ \mathrm{~kW}^{-1}\right)$;

(m) fraction of the system cost, which is spent on its maintenance and repairs.

In accordance with the term of (2.38), it corresponds to the maintenance and repair of the system annual cost (MRAC) that affects the economical diameter calculation.

The unit cost of the active system components $\left(C_{\mathrm{ua}}\right)$ is calculated in the following way for the combustion and the electrical systems, respectively:

$$
\begin{gathered}
C_{\mathrm{ua}}=\frac{P_{p}+P_{\mathrm{cce}}}{\text { Pow }_{\mathrm{ber}}}, \\
C_{\mathrm{ua}}=\frac{P_{p}+P_{\mathrm{em}}+P_{s}+P_{\mathrm{et}}+P_{\mathrm{ea}}}{\text { Pow }_{\mathrm{ber}}},
\end{gathered}
$$

where

$\left(P_{p}\right)$ purchase price of the hydraulic pump $(\$)$;

$\left(P_{\text {cce }}\right)$ purchase price of the complete combustion engine, that is, with all the components to operate it (injector pump, fuel tank, battery, starter, cooler, etc.);

$\left(P_{\mathrm{em}}\right)$ purchase price of the electric motor $(\$)$;

$\left(P_{\mathrm{cp}}\right)$ starter price $(\$)$;

$\left(P_{\text {et }}\right)$ electric transformer price $(\$)$;

$\left(P_{\mathrm{cp}}\right)$ price of the electric accessories, such as cables, connectors, separators, capacitor bank, and so forth;

(Pow ber $_{\text {) }}$ power developed by the components within the best effectiveness range $(\mathrm{kW})$.

Thus, the derivative of (2.38), which should be included in (2.28), (2.30), (2.32), (2.34), and (2.36), becomes

$$
\begin{aligned}
\left(K_{1}+\right. & \left.K_{2}\right) K_{6} K_{4} C_{\mathrm{ub}}\left(-5 \phi^{-6} f+\frac{d f}{d \phi} \phi^{-5}\right) \\
& +\left[K_{6} K_{4} C_{\mathrm{ub}}\left(-5 \phi^{-6} f+\frac{d f}{d \phi} \phi^{-5}\right)+\mathrm{Lab} \phi^{b-1}\right] m .
\end{aligned}
$$

Again, equaling (2.28), (2.30), (2.32), (2.34), and (2.36), added to (2.40), to zero, one obtains the economic discharge piping diameter in the second approach.

As may be noted, the manual resolution of these equations is a very laborious and impracticable process. But with the computer program (integrated electronic forms) 
PRODIVE - program for calculation of the diameter and economic discharge-this process is fast.

\section{Application of the model}

The developed model was applied, through PRODIVE, to a water elevating system to supply a center pivot irrigation equipment type of 90.94 ha, already installed at an agricultural property in Itapura (SP) Brazil. Thus, it was possible to make a comparison between the observed discharge diameter/velocity and the one calculated by the model.

The elevating system data required for application of the model are as follows.

(i) Basic hydraulic data:
(a) system outflow: $341 \mathrm{~m}^{3} \mathrm{~h}^{-1}$;
(b) discharge piping length: $1452 \mathrm{~m}$;
(c) material: zinc steel with elastic joint (absolute roughness $=0.0002 \mathrm{~m}$ );
(d) geometric elevation height: $23.2 \mathrm{~m}$;
(e) piezometric load required at the end of the discharge piping: $45.8 \mathrm{~m}$;
(f) expected effectiveness for the motor pump unit (1st approach): 70\%.

(ii) Basic economical data:
(a) annual interest rate: $8.75 \%$;
(b) residual value of the system: 10\%;
(c) amortization period of the system: 15 years;
(d) annual expenses with maintenance and repairs: 2\% of the indicial investment.

(iii) Data of the multiplicative regression between the discharge piping diameter ( $\phi$ in meters) and its installed unit cost $\left(\$ \mathrm{~m}^{-1}\right)$ :
(a) price $=a \phi^{b}$;
(b) where: $a=436.59$ and $b=1.19223$;
(c) minimum level of significance of the regression: 0.00053 ;
(d) determination coefficient $\left(R^{2}\right): 98.85 \%$.

(iv) Combustion engine data:
(a) type of fuel: diesel;
(b) fuel price: $\$ 1.57 \mathrm{~L}^{-1}$;
(c) unit fuel consumption: $0.225 \mathrm{~L} \mathrm{hp}^{-1} \mathrm{~h}^{-1}$;
(d) annual length of operation: $2400 \mathrm{~h}$;
(e) expected hydraulic pump effectiveness (2nd approach): 79\%.

(v) Electrical system data in conventional billing (with and without discount):
(a) number of days per year of system-operation: 120;
(b) daily length of system-operation: $20 \mathrm{~h}$;
(c) number of months per year without operating the system: 4;
(d) conventional demand billing: $\$ 9.78 \mathrm{~kW}^{-1}$;
(e) conventional consumption billing: $\$ 0.14298 \mathrm{kWh}^{-1}$;
(f) daily length of system-operation from $11 \mathrm{pm}$ to $5 \mathrm{am}$ (special time with dis- count for irrigation): $6 \mathrm{~h}$;


(g) fraction of discount on the consumption tariff for irrigation from $11 \mathrm{pm}$ to 5 am: 0.70 ;

(h) expected motor pump unit effectiveness (2nd approach): 75\%.

(vi) Electrical system data at hourly-seasonal green tariff (with and without discount):

(a) number of days of system-operation in dry period: 100;

(b) daily length of system-operation at off-peak time in dry period: $20 \mathrm{~h}$;

(c) daily length of system-operation at peak time in dry period: $0 \mathrm{~h}$;

(d) number of days of system-operation in wet period: 20;

(e) daily length of system-operation at off-peak time in wet period: $20 \mathrm{~h}$;

(f) daily length of system-operation at peak time in wet period: $0 \mathrm{~h}$;

(g) number of months per year without operating the system: 4;

(h) green hourly-seasonal demand billing: $\$ 8.60 \mathrm{~kW}^{-1}$;

(i) consumption green hourly-seasonal billing at off-peak time in dry period: $\$ 0.08048 \mathrm{kWh}^{-1}$;

(j) consumption green hourly-seasonal billing at peak time in dry period: $\$ 0.76598 \mathrm{kWh}^{-1}$;

(k) consumption green hourly-seasonal billing at off-peak time in wet period: $\$ 0.07115 \mathrm{kWh}^{-1}$;

(1) consumption green hourly-seasonal billing at peak time in wet period: $\$ 0.75339 \mathrm{kWh}^{-1}$;

(m) daily length of system-operation from $11 \mathrm{pm}$ and 5 am in dry period (special time with discount for irrigation): $6 \mathrm{~h}$;

(n) daily length of system-operation from $11 \mathrm{pm}$ and 5 am in wet period (special time with discount for irrigation): $6 \mathrm{~h}$;

(o) fraction of discount on the consumption tariff for irrigation from $11 \mathrm{pm}$ to 5 am: 0.70;

(p) expected motor pump unit effectiveness (2nd approach): 75\%.

The application results of the model can be seen in Table 3.1.

According to Table 3.1, it is found that the difference between the first and the second approach was small. This was partly due to the similarity of the expected effectiveness in both the first approach and second approach, and also, because the fixed annual cost of the active system components, present only in the second approach, presented the same tendency as the fixed annual cost presented by the discharge piping in the total annual cost in the first approach.

With regard to the economic velocity, it was found that the system velocity with hydraulic pump driven by a diesel engine presented a lower value $\left(0.94 \mathrm{~ms}^{-1}\right)$. This was due, not only to the higher annual pumping cost, but also to the higher fixed annual cost of the active system components in the composition of the fixed annual cost and, consequently, in the total annual cost. Thus, the economic diameter in this system was the highest found $(357.4 \mathrm{~mm})$.

As regards to the electric power billing modality, it is noted that as the system was not used at peak times, the annual pumping cost for hourly-seasonal green tariff rate 
Table 3.1. Economic diameter and economic flow velocity of the system with different types of hydraulic pump drives and electric power tariffs.

\begin{tabular}{l|cccc}
\hline \multirow{2}{*}{ Type of system } & \multicolumn{2}{|c}{ 1st approach } & \multicolumn{2}{c}{ 2nd approach } \\
\cline { 2 - 5 } & $\mathbf{D}(\mathrm{mm})$ & $\mathbf{v}(\mathrm{m} / \mathrm{s})$ & $\mathbf{D}(\mathrm{mm})$ & $\mathbf{v}(\mathrm{m} / \mathrm{s})$ \\
\hline Combustion: diesel & 363.0 & 0.92 & 357.4 & 0.94 \\
Electricity: CT—without discount & 310.2 & 1.25 & 308.2 & 1.27 \\
Electricity: CT-with discount & 301.3 & 1.33 & 300.9 & 1.33 \\
Electricity: green HST-without discount & 287.4 & 1.46 & 289.8 & 1.44 \\
Electricity: green HST—with discount & 280.1 & 1.54 & 284.1 & 1.49 \\
\hline
\end{tabular}

presented a smaller participation in the total annual cost. Therefore, the diameter of the piping became shorter, linked to the fact that the fixed cost of the active system components do not have higher share in the composition of the fixed annual and, consequently, in the total annual cost. When the discharge piping is much longer, it has a major share in the fixed annual cost and in the interval of the economic diameter of the system, in comparison with the active system component. This reasoning is also applied in each modality when one applies the discount for irrigation at night (Decree 105 of 1992, DNAEE, National Water and Electric Power Department, Brazil).

When comparing the diameter of the actual condition, $250 \mathrm{~mm}$, with the diameter of $284.1 \mathrm{~mm}$, calculated by the model under the condition corresponding to the tariff charged to the property, it was necessary to generate, transmit, and distribute extra electric power, due to the major load loss caused by the original diameter, of approximately $30800 \mathrm{kWh}$ per year. This means that in one year, the consumer would spend $\mathrm{R} \$ 2,804.00$ more on the cost of pumping alone. At this rate, the discharge piping should consist of a $1150 \mathrm{~m}$ long segment $300 \mathrm{~mm}$ in diameter, and another $302 \mathrm{~m}$ long segment, $250 \mathrm{~mm}$ in diameter, to be equivalent to the economic pipe.

\section{Conclusion}

In accordance with the proposal of the work, it can be concluded that

(i) the developed model made it possible to calculate the diameter and economic velocity for each type of hydraulic pump driving an elevating system, electric power billing modality, and checking whether or not the special discount for nightly irrigation was of benefit;

(ii) By application of the model it was found that the diameter of $250 \mathrm{~mm}$ used by consumer, in comparison with the economic diameter of $284.1 \mathrm{~mm}$, causes extra $30800 \mathrm{kWh}$ per year electric power consumption.

\section{Acknowledgments}

The authors are indebted to Lygia Beatriz Tangerino Junqueira for translating this paper into English. The authors also express their gratefulness to the Foundation for Development of UNESP (FUNDUNESP) that will grant them financial support for the publication in MPE. 


\section{References}

[1] H. E. Babbitt, Abastecimento de água, Blücher, São Paulo, 1973, translated by Z. C. Branco.

[2] T. R. Camp, Water distribution, Handbook of Applied Hydraulics (C. V. Davis, ed.), chapter 20, McGraw-Hill, New York, 1952, pp. 881-944.

[3] E. M. Coiado and A. Rivelli Jr., Influência da evolução do cost da energia elétrica no diâmetro econômico de uma instalação de recalque de água de abastecimento, Revista Brasileira de Engenharia - Caderno de Recursos Hídricos 11 (1993), no. 2, 27-48.

[4] A. R. Cuomo and S. M. Villela, Dimensionamento econômico de tubulações em recalque, EESC, São Carlos, 1961, (Issue 46).

[5] A. K. Deb, Optimization in design of pumping systems, Journal of the Environmental Engineering Division 104 (1978), no. 1, 127-136.

[6] A. Lencastre, Hidráulica geral, Hidroprojecto, Lisboa, 1983.

[7] E. T. Neves, Custo de hidráulica, 7th ed., Globo, Porto Alegre, 1982.

[8] J. L. Zocoler, Modelo para dimensionamento econômico de sistemas de recalque em projetos hidroagrícolas. Piracicaba, Thesis (Doctorate), Escola Superior de Agricultura "Luiz de Queiroz", Universidade de São Paulo, São Paulo, 1998.

[9] __ Modelo matemático para cálculo dos custos e otimização de sistemas de bombeamento. Ilha Solteira, Thesis (Free-Docency), Faculdade de Engenharia, Universidade Estadual Paulista, São Paulo, 2003.

João L. Zocoler: Phytosanity Department, Rural and Soil Engineering, FEIS, Universidade Estadual Paulista (UNESP), 15385-000 Ilha Solteira, SP, Brazil

E-mail address: zocoler@agr.feis.unesp.br

Francisco C. Baggio Filho: Agronomy Department, FEIS, Universidade Estadual Paulista (UNESP), 15385-000 Ilha Solteira, SP, Brazil

E-mail address: xikobaggio@terra.com.br

Luís A. F. Oliveira: Mathematics Department, FEIS, Universidade Estadual Paulista (UNESP), 15385-000 Ilha Solteira, SP, Brazil

E-mail address: lafo@fqm.feis.unesp.br

Fernando B. T. Hernandez: Phytosanity Department, Rural and Soil Engineering, FEIS, Universidade Estadual Paulista (UNESP), 15385-000 Ilha Solteira, SP, Brazil

E-mail address: fbhtang@agr.feis.unesp.br 


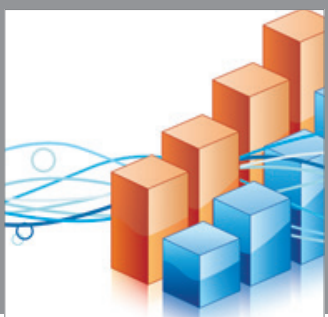

Advances in

Operations Research

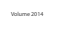

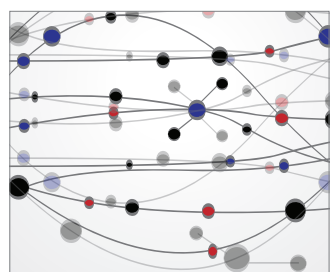

\section{The Scientific} World Journal
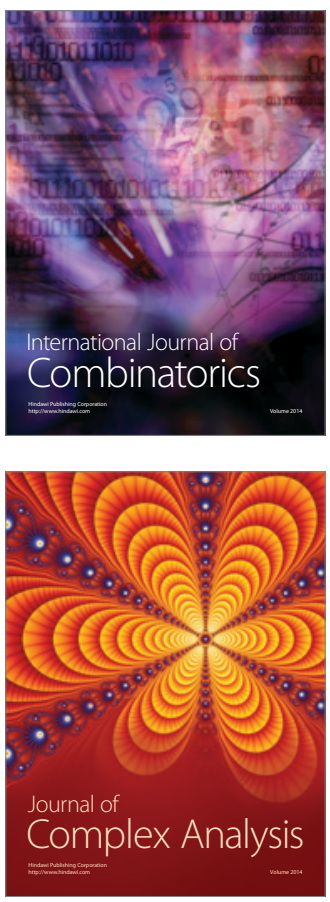

International Journal of

Mathematics and

Mathematical

Sciences
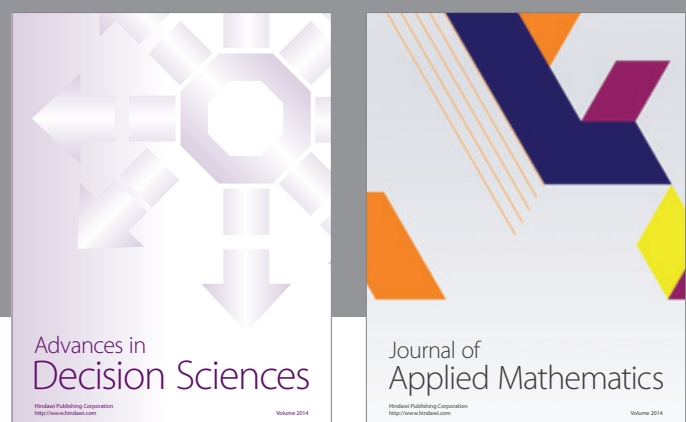

Journal of

Applied Mathematics
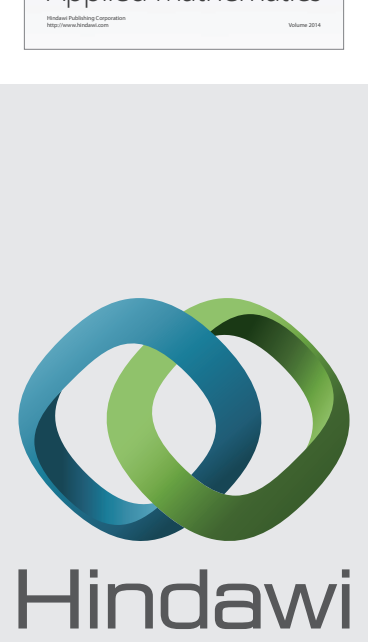

Submit your manuscripts at http://www.hindawi.com
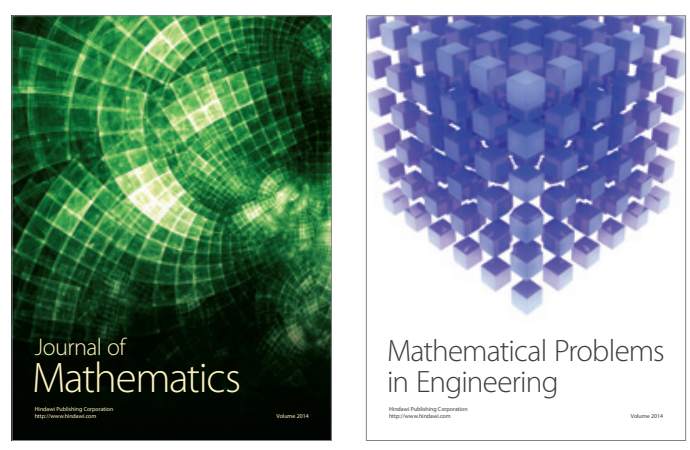

Mathematical Problems in Engineering
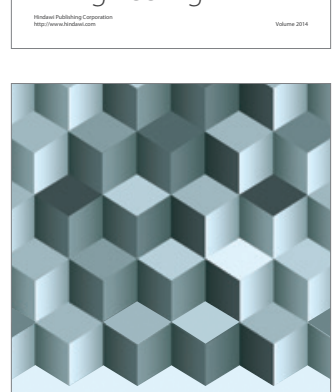

Journal of

Function Spaces
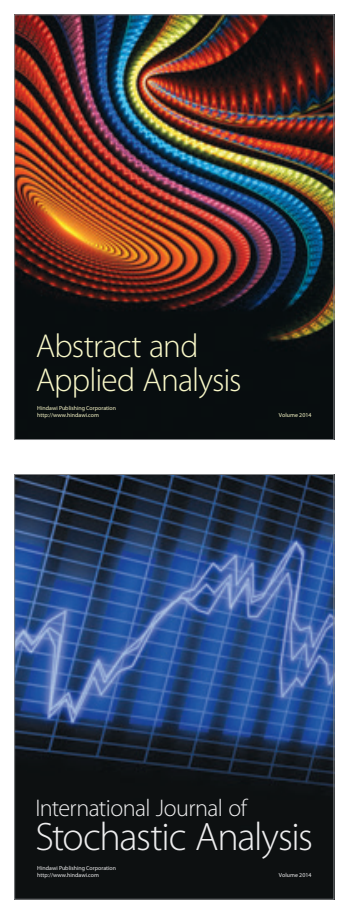

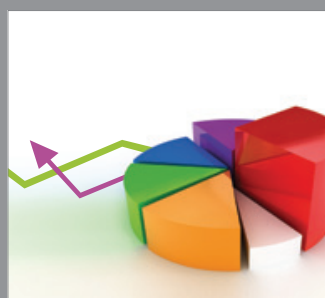

ournal of

Probability and Statistics

Promensencen
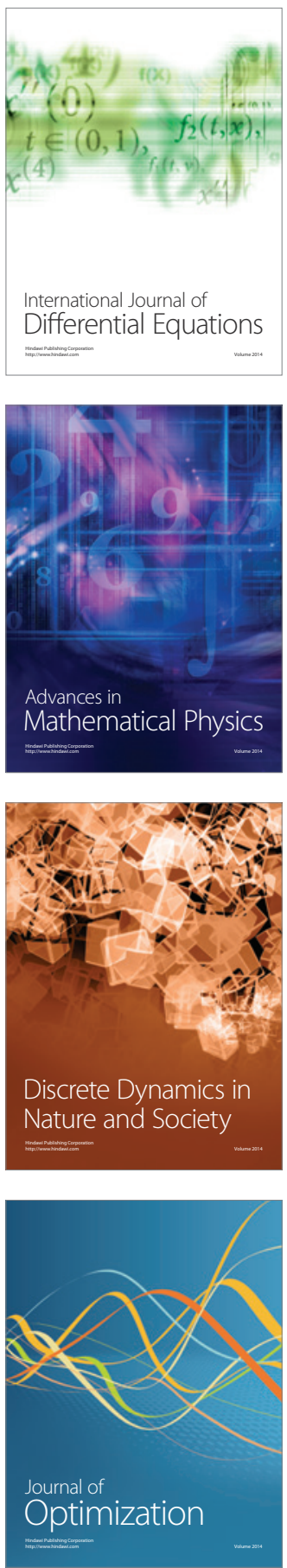